\title{
Colic induced by lead
}

\section{Tzung-Hai Yen MD PhD, Ja-Liang Lin MD, Cheng-Hao Weng MD, Chung-Chih Tang MD}

Previously published at www.cmaj.ca

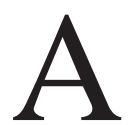

23-year-old lead battery recycling worker was referred for abdominal pain that he had for two months. He described the pain as intermittent and colicky, but without any aggravating or relieving factors. His medical history was unremarkable. On physical examination, he had a soft and diffusely tender abdomen without peritoneal signs. Neurologic examination was normal.

Blood tests showed microcytic anemia with a hemoglobin of 110 (normal 135-175) $\mathrm{g} / \mathrm{L}$, hematocrit of 0.36 (normal $0.41-0.53$ ) and mean corpuscular volume of 64.7 (normal 80-100) fL. A blood smear (Figure 1) showed microcytic erythrocytes with prominent basophilic stippling. Because of the patient's occupation, urine was screened for toxic metals (antimony, arsenic, bismuth, cadmium, copper, manganese, mercury, nickel, lead, tellurium, thallium, zinc). The lead concentration in the blood and urine was very high at 6.3 (normal < 1.9) $\mu \mathrm{mol} / \mathrm{L}$ and 3.9 (normal < 1.1) $\mu \mathrm{mol} / \mathrm{L}$, respectively. However, results of nerve conduction studies and electromyography were normal. Chelation therapy with ethylenediaminetetraacetic acid (EDTA) and dimercaptopropanesulfonic acid (DMPS) was started. The patient's symptoms improved and levels of lead in the blood decreased to $3.0 \mu \mathrm{mol} / \mathrm{L}$ and $2.0 \mu \mathrm{mol} / \mathrm{L}$ after one and two weeks, respectively.

Exposures to lead can occur with leaded gasoline, some industries, contaminated water, and lead-containing paints and herbal drugs. Elevated levels of lead in the blood are also associated with male sex, low educational level, smoking, alcohol consumption and level of urbanization. ${ }^{1}$ Infants and children have a greater risk of lead poisoning. The overall incidence rates of lead toxicity have decreased in most developed countries because of increased public awareness and removal of lead from gasoline and paint products. Conversely, lead pollution remains a serious problem in developing countries. ${ }^{2}$ The symptoms of lead poisoning include impaired cognition, abdominal pain, irritability, impotence,

From the Department of Nephrology (Yen, Lin, Weng), the Division of Hematology-Oncology (Tang), Chang Gung Memorial Hospital, Taipei, and the College of Medicine (Yen, Lin, Weng, Tang), Chang Gung University, Taoyuan, Taiwan

\section{CMAJ 2010. DOI:10.1503/cmaj.091095}

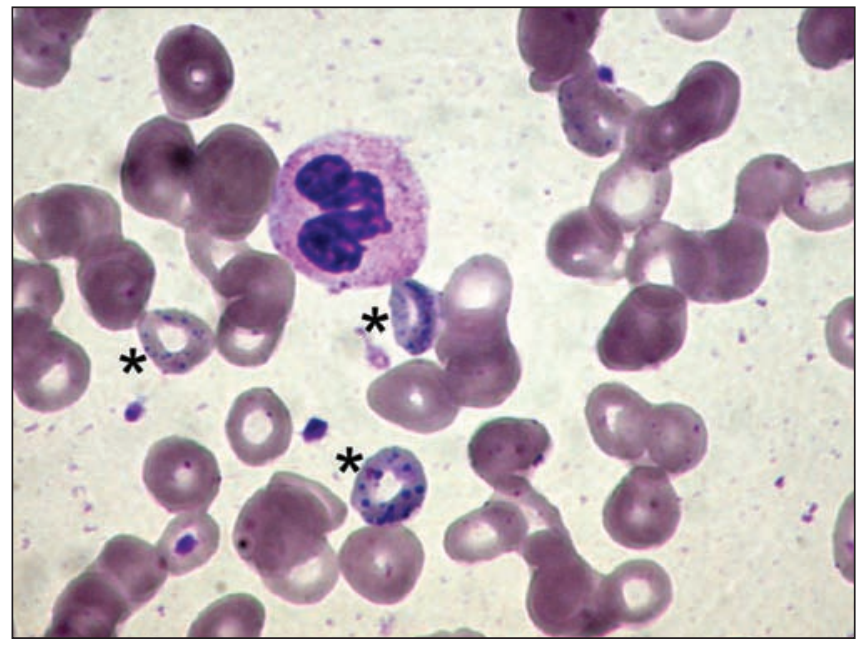

Figure 1: Microscopic view of a peripheral blood smear (original magnification $\times 1000$ ) from a 23 -year-old man with lead toxicity, showing microcytic erythrocytes with prominent basophilic stippling (asterisks).

insomnia, a metallic taste in the mouth and headache. In severe cases, it can lead to seizures, coma and death. The hematologic effects of lead poisoning are decreased hemoglobin synthesis and hemolysis. Lead may cause irreversible neurologic damage, as well as renal disease, cardiovascular effects and reproductive toxicity. Treatment options depend on the level of lead in the blood. Low levels may be safely treated with a decrease in environmental exposure, but high levels should be treated with chelators. ${ }^{3}$

This article has been peer reviewed.

Competing interests: None declared.

\section{REFERENCES}

1. Liou SH, Wu TN, Chiang HC, et al. Blood lead levels in Taiwanese adults: distribution and influencing factors. Sci Total Environ 1996;180:211-9.

2. Chang E. Plants shut for lead poisoning in south China; thousands sickened. CNN News; 2009. Available: http://edition.cnn.com/2009/WORLD/asiapcf/09/02/china lead.poisoning.hunan/index.html (accessed 2009 Sept. 6)

3. Kosnett MJ, Wedeen RP, Rothenberg SJ, et al. Recommendations for medical management of adult lead exposure. Environ Health Perspect 2007;115:463-71. 